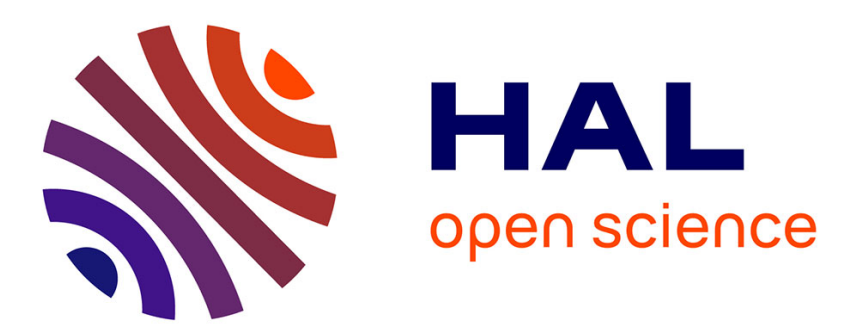

\title{
Comparison between magnetic-hyperfine-structure parameters in Sci and TII
}

\author{
C. Bauche-Arnoult, J.-J. Labarthe
}

\section{To cite this version:}

C. Bauche-Arnoult, J.-J. Labarthe. Comparison between magnetic-hyperfine-structure parameters in Sci and TII. Journal de Physique Lettres, 1975, 36 (12), pp.285-287. 10.1051/jphyslet:019750036012028500 . jpa-00231210

\section{HAL Id: jpa-00231210 https://hal.science/jpa-00231210}

Submitted on 1 Jan 1975

HAL is a multi-disciplinary open access archive for the deposit and dissemination of scientific research documents, whether they are published or not. The documents may come from teaching and research institutions in France or abroad, or from public or private research centers.
L'archive ouverte pluridisciplinaire HAL, est destinée au dépôt et à la diffusion de documents scientifiques de niveau recherche, publiés ou non, émanant des établissements d'enseignement et de recherche français ou étrangers, des laboratoires publics ou privés. 


\title{
COMPARISON BETWEEN MAGNETIC-HYPERFINE-STRUCTURE PARAMETERS IN ScI AND TiI
}

\author{
C. BAUCHE-ARNOULT and J.-J. LABARTHE \\ Laboratoire Aimé-Cotton, C.N.R.S. II, Bât. 505, 91405 Orsay, France
}

(Reçu le 5 septembre 1975, accepté le 18 septembre 1975)

\begin{abstract}
Résumé. - Les effets de second ordre dus à l'interaction de configuration sur les paramètres concernant les parties de structure hyperfine magnétique dépendant de l'orbite ont été évalués $a$ priori dans les termes fondamentaux du Scandium et du Titane. Les importances relatives des différentes excitations sont discutées. Les valeurs du rapport $\alpha=a_{1} / a_{\mathrm{sC}}$ obtenues dans Sc et Ti sont respectivement 1,07 et 1,05 .
\end{abstract}

Abstract. - $A b$ initio calculations of the second-order effects of the configuration interaction on the orbit-dependent magnetic-hyperfine-structure parameters in the $3 \mathrm{~d}^{N} 4 \mathrm{~s}^{2}$ configuration have been performed. The importance of the contributions of the different excitations is discussed and a comparison is made between $\mathrm{Sc}$ and $\mathrm{Ti}$. The ratio $\alpha=a_{\mathrm{l}} / a_{\mathrm{sC}}$ is found to be 1.07 and 1.05 in $\mathrm{Sc}$ and $\mathrm{Ti}$ respectively.

To take into account the effects of the configuration interaction on the hyperfine structure, three radial parameters are needed, for a given pure RussellSaunders term. They correspond to the three parts of the magnetic effective hamiltonian : the orbital part, the spin dipole part and the core polarization part. This means that the $\left\langle r^{-3}\right\rangle$ quantities are different for the orbital part and for the spin dipole part. It is convenient, in the case of a pure Russell-Saunders term $\alpha \mathrm{SL}$ of an $1^{N}$ configuration, to define correction factors $\Delta_{x}$ such as

$$
\left\langle r_{x}^{-3}\right\rangle=\left(1+\Delta_{x}\right)\left\langle r^{-3}\right\rangle \quad(x \equiv 1 \text { or } \mathrm{sC})
$$

where $\Delta_{x}$ depends on $\alpha \mathrm{SL}$.

Using the second order perturbation theory, the $\Delta$ factors can be written as linear combinations of radial integrals arising from the different excitations which occur. Bauche-Arnoult [1] gives the formal expression of the $\Delta$ factors for the Hund terms of $\mathrm{d}^{N}$ and $\mathrm{f}^{N}$ configurations. These expressions exhibit some striking features : the formal expression of $\Delta_{1}-\Delta_{\mathrm{sC}}$ is the same for $\mathrm{d}$ and $\mathrm{d}^{2}, \mathrm{~d}^{3}$ and $\mathrm{d}^{4}, \mathrm{~d}^{6}$ and $d^{7}, d^{8}$ and $d^{9}$, except for the part arising from the excitation $d \rightarrow g$. The ratio of $h f s$ parameters

$$
\alpha=\frac{a_{1}}{a_{\mathrm{sC}}}=\frac{1+\Delta_{1}}{1+\Delta_{\mathrm{sC}}}
$$

which can be written $1+\left(\Delta_{1}-\Delta_{\mathrm{sC}}\right)$ since the $\Delta$ correction factors are small compared to unity, should therefore have the same value for the Hund terms of two neighbouring elements (if we assume that the similar radial integrals change very little from one element to the next one in the series and if we neglect the contribution of the $d \rightarrow g$ excitation).

In the $3 \mathrm{~d}^{N} 4 \mathrm{~s}^{2}$ series, the pairs are $(\mathrm{Sc}, \mathrm{Ti}),(\mathrm{V}, \mathrm{Cr})$, $(\mathrm{Fe}, \mathrm{Co})$ and $(\mathrm{Ni}, \mathrm{Cu})$. Childs and Greenebaum [2] have gathered the experimental data avialable in this series. For $\mathrm{Fe}$ and $\mathrm{Co}$ the data agree well with the prediction since $\alpha_{\mathrm{Fe}}=0.94 \pm 0.03$ and $\alpha_{\mathrm{Co}}=0.924$. Unfortunately the ground configurations of $\mathrm{Cr}$ and $\mathrm{Cu}$ are not of the $3 \mathrm{~d}^{N} 4 \mathrm{~s}^{2}$ type and therefore these hyperfine structures have not been measured by atomic beam resonance. Furthermore, in $\mathrm{Cu}$, the distance between ${ }^{2} \mathrm{D}_{3 / 2}$ and ${ }^{2} \mathrm{D}_{5 / 2}$ is $2042 \mathrm{~cm}^{-1}$. This would not allow the off-diagonal hyperfinestructure studies which are necessary if we consider the three independent parts of the hamiltonian.

For these reasons our attention has been drawn to the pair (Sc, Ti). Several experiments have been performed. Fricke et al. [3] have measured the hfs of the ${ }^{2} \mathrm{D}$ levels of Sc. Childs [4] has been able to determine the off-diagonal hyperfine-structure, because the distance between ${ }^{2} D_{3 / 2}$ and ${ }^{2} D_{5 / 2}$, here, is only $168 \mathrm{~cm}^{-1}$. The values of the three magnetic hfs parameters lead to the ratio $\alpha=1.13_{-0.10}^{+0.27}$. As concerns $\mathrm{Ti}$, Childs [2] has deduced, from the experimental result on the three levels ${ }^{3} \mathrm{P}$ of Channappa and Pendlebury [5], $\alpha=1.03$. We concluded, at that time, that the prediction was valid. However, more recently, Gebauer et al. [6] have obtained in Sc a value of $\alpha$ with a much better accuracy : $\alpha=1.123 \pm 0.010$. 
TABLE I

Analytical

\section{Contribution}

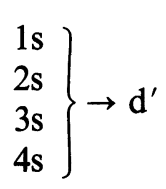

$-\bar{\Delta}_{\mathrm{s}} \mathrm{C}^{2}$

$-\Delta_{\mathrm{sc}}{ }^{2}$

$-\Delta_{\mathrm{s}} \mathrm{C}^{2}$

$-\Delta_{\mathrm{sC}^{2}}$

$\left.\begin{array}{l}2 \mathrm{p} \\ 3 \mathrm{p}\end{array}\right\} \rightarrow \mathrm{p}^{\prime}$

$\left.\begin{array}{l}2 \mathrm{p} \\ 3 \mathrm{p}\end{array}\right\} \rightarrow \mathrm{f}^{\prime}$

$\left.\begin{array}{l}1 s \\ 2 s \\ 4 s\end{array}\right\} \rightarrow 3 d$

3d $\rightarrow s^{\prime}$

$3 \mathrm{~d}\} \rightarrow \mathrm{d}^{\prime}$

3d $\rightarrow \mathrm{g}^{\prime}$
$\Delta_{1}-\Delta_{\mathrm{sC}}{ }^{2}$

$\Delta_{1}-\Delta_{\mathrm{sC}^{2}}$

$-\Delta_{\mathrm{s} \mathrm{C}^{2}}$

$-\Delta_{\mathrm{s} \mathrm{C}^{2}}$

$-\Delta_{\mathrm{s} \mathrm{C}^{2}}$

$-\Delta_{\mathrm{s}} \mathrm{S}^{2}$

$-\Delta_{\mathrm{sC}^{2}}$

$-\Delta_{\mathrm{sc}}$

$-\Delta_{\mathrm{sC}^{2}}$

$\Delta_{1}-\Delta_{\mathrm{sc}^{2}}$

$-\Delta_{\mathrm{sC}^{2}}$

Total
Sc

$-0.000687$

$-0.010284$

$-0.004625$

$-0.000705$

$+0.085089$

$+0.052878$

$-0.016008$

$-0.020286$

$-0.000020$

$-0.003364$

$-0.009363$

$+0.000316$

0
0
0

$+0.072941$

Therefore, in order to understand the discrepancy between $\alpha_{\mathrm{Ti}}$ and $\alpha_{\mathrm{Sc}}$, we performed ab initio evaluations of the $\alpha$ quantities.

For each configuration of the type : $1 s^{2} 2 s^{2} 2 p^{6} 3 s^{2}$ $3 p^{6} 3 d^{N} 4 s^{2}$, seven kinds of excitations can occur :

i) excitations from a closed shell to an empty shell :

$$
\begin{aligned}
& 1 \mathrm{~s}, 2 \mathrm{~s}, 3 \mathrm{~s}, 4 \mathrm{~s} \rightarrow \mathrm{d}^{\prime} \\
& 2 \mathrm{p}, 3 \mathrm{p} \rightarrow \mathrm{p}^{\prime} \\
& 2 \mathrm{p}, 3 \mathrm{p} \rightarrow \mathrm{f}^{\prime}
\end{aligned}
$$

ii) excitations from a closed shell to the open shell :

$$
1 \mathrm{~s}, 2 \mathrm{~s}, 3 \mathrm{~s}, 4 \mathrm{~s} \rightarrow 3 \mathrm{~d}
$$

iii) excitations from the open shell to an empty shell:

$$
3 d \rightarrow s^{\prime}, d^{\prime}, g^{\prime}
$$

(we note that the excitations of a closed shell 1s, $2 \mathrm{~s}$, $3 s$, 4 s to an empty shell s' give a contribution only to the Fermi contact term, that we do not consider here).

From Bauche-Arnoult [1] the formal expression of $\Delta_{1}-\Delta_{\mathrm{sC}}$ is the same for $\mathrm{Sc}$ and Ti for the excitations i) and ii). In the third case, $\Delta_{1}-\Delta_{\mathrm{sc}}$ is zero for $3 \mathrm{~d} \rightarrow \mathrm{s}^{\prime}$ and $\mathrm{d}^{\prime}$ for both elements. $3 \mathrm{~d} \rightarrow \mathrm{g}^{\prime}$ gives 0 for $\mathrm{Sc}$ and a non zero value for $3 \mathrm{~d}^{2} 4 \mathrm{~s}^{2}{ }^{3} \mathrm{~F}$ of Ti.

The separate effects of each excitation can be described in terms of one virtual orbital since the excitations involve only one electron. Each virtual orbital was determined as an analytical function by optimization [7]. For each of the largest contributions to $\Delta_{1}$ and $\Delta_{\mathrm{sC}}(>0.01)$, it appeared feasible to check our result by making another calculation, using a Multiconfigurational Hartree-Fock program (MCHF) [8]. The MCHF procedure has been used

$$
\begin{gathered}
\mathrm{Ti} \\
-0.000712 \\
-0.010925 \\
-0.002862 \\
-0.000427 \\
+0.079477 \\
+0.018662 \\
-0.015251 \\
-0.017684 \\
-0.000024 \\
-0.003632 \\
-0.007931 \\
+0.000122 \\
0 \\
0 \\
+0.008635 \\
+0.047448
\end{gathered}
$$

here for obtaining the virtual orbital relevant to the true second order effect, that is, with vanishing weights for all excited configurations. In the five cases that we considered, the results obtained by the two methods are very close (Table I).

If we examine each excitation separately, we see that $2 p, 3 p \rightarrow p^{\prime}$ give contributions much larger than the other ones, due to the large spatial overlapping of the radial functions. The following ones in order of importance are $2 \mathrm{p}, 3 \mathrm{p} \rightarrow \mathrm{f}^{\prime}$, the excitations of the $n$ s closed shells being ten times weaker.

Comparing $\mathrm{Sc}$ and $\mathrm{Ti}$ we see that, except for $3 p \rightarrow p^{\prime}$, the large contributions do not differ by more than $20 \%$. For the inner shells $1 \mathrm{~s}, 2 \mathrm{~s}$ and $2 \mathrm{p}$, the differences are very small : less than $10 \%$. For 3 s and 4s they are somewhat larger.

The sum of the contributions of the different excitations to $\Delta_{1}-\Delta_{\mathrm{sC}}$ is given at the bottom of the table. Omitting the last figures, we have summarized the results in table II. The effects of relativity are expected to be about $1 \%$ for both $\mathrm{Sc}$ and $\mathrm{Ti}$, reducing the calculated value of $\alpha$ [9].

In conclusion, as it was expected [1], when we consider the second order effects, the $a b$ initio evaluations of $\alpha$ for Sc and Ti lead to values which are close (in spite of the excitation $\mathrm{d} \rightarrow \mathrm{g}$ in $\mathrm{Ti}$, which turns

\section{TABLE II}

$\begin{array}{lcc} & \mathrm{Sc} & \mathrm{Ti} \\ \alpha_{\text {calculated }} & - & - \\ \alpha_{\text {calc. with relativity }} & 1.07 & 1.05 \\ \alpha_{\text {experimental }} & 1.06 & 1.04 \\ & 1.12 \pm 0.01 & 1.03\end{array}$


out to be $1 \%$ of the $\alpha_{\mathrm{Ti}}$ value). The problem of the bad agreement with the experimental $\alpha_{\mathrm{Sc}}$ value remains. However : on the one hand, the configuration-mixing wave functions are not yet known for the even low levels of $\mathrm{ScI}$; on the other hand, calculations including higher-order effects, in particular near-degeneracy effects, would be of great interest. In order to check the agreement with other experimental results, similar second-order calculations for the other elements of the series would be instructive.

\section{References}

[1] Bauche-Arnoult, C., Proc. R. Soc. A 322 (1971) 361

[2] Childs, W. J. and Greenebaum, B., Phys. Rev. A 6 (1972) 105.

[3] Fricke, G., Kopfermann, H., Penselin, S. and Schlupmann, Z., Z. Phys. 156 (1959) 416.

[4] Childs, W. J., Phys. Rev. A 4 (1971) 1767.

[5] Channappa, K. H. and Pendlebury, J. M., Proc. Phys. Soc. 86 (1965) 1145
[6] Gebauter, H., Aldenhoven, R. and Aydin, R., Phys. Lett. 51A (1975) 417.

[7] Labarthe, J.-J., J. Phys. B : Atom. Molec. Phys. 6 (1973) 1761.

[8] Froese-Fischer, C., Comput. Phys. Commun. 1 (1970) 151.

[9] Rosen, A., Phys. Scripta 8 (1973) 154. 